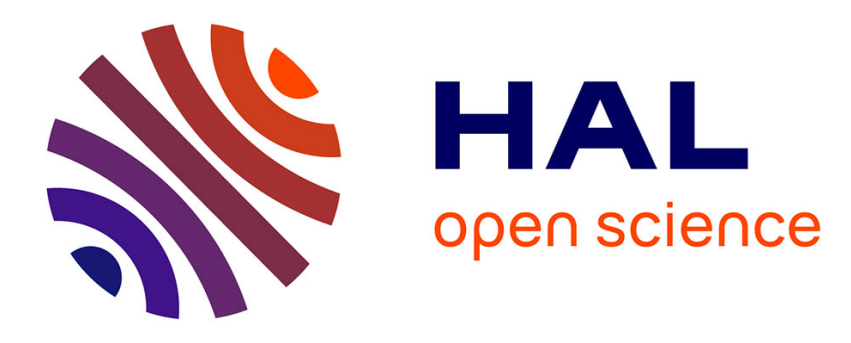

\title{
A study of mixed-mode dynamic crack initiation in PMMA
}

\author{
Daniel Rittel, Hubert Maigre
}

\section{To cite this version:}

Daniel Rittel, Hubert Maigre. A study of mixed-mode dynamic crack initiation in PMMA. Mechanics

Research Communications, 1996, 23, pp.475-481. 10.1016/0093-6413(96)00047-X . hal-00111562

\section{HAL Id: hal-00111562 \\ https://hal.science/hal-00111562}

Submitted on 9 Sep 2019

HAL is a multi-disciplinary open access archive for the deposit and dissemination of scientific research documents, whether they are published or not. The documents may come from teaching and research institutions in France or abroad, or from public or private research centers.
L'archive ouverte pluridisciplinaire HAL, est destinée au dépôt et à la diffusion de documents scientifiques de niveau recherche, publiés ou non, émanant des établissements d'enseignement et de recherche français ou étrangers, des laboratoires publics ou privés. 


\title{
A STUDY OF MIXED-MODE DYNAMIC CRACK INITIATION IN PMMA
}

\author{
D. Rittel and H. Maigre 1 \\ Faculty of Mechanical Engineering, Technion \\ 32000, Haifa, Israel
}

$\underline{\text { Introduction }}$

The effect of mode-mix on crack initiation (toughness and trajectory) is well documented both theoretically and experimentally for quasi-static fracture [1]. Dynamic fracture (single or mixed-mode) analysis is generally more complicated since inertial effects cannot be neglected [2].

Recent (mode II) shear impact experiments in steel and polycarbonate have shown the existence of fracture mode transitions (brittle to ductile, including shear band formation) as a function of the impact velocity [3-5].

Here we report experimental results for mixed-mode dynamic crack initiation in commercial PMMA as a model for brittle materials. The two-dimensional combination of a major and a minor mode (I-II or II-I respectively) was systematically achieved using two distinct specimen geometries impacted at various velocities. The results show that, regardless of the dominant loading mode, the initial kink angle between the crack and the original notch line increase with the impact velocity.

These results are described and discussed in terms of a simple criterion.

\section{General framework}

The history of the dynamic stress intensity factor(s) (SIF) can be determined by hybrid experimental-numerical techniques relying on the use of path-independent integrals or dynamic weight functions $[2,6,7]$. In these reports, the dynamic SIFs are determined either from the experimental forces or from the experimental displacements.

Experimental investigation of dynamic crack initiation under single loading mode (e.g. mode I) can be achieved by keeping both the specimen's geometry and the loading

${ }^{1}$ LMS Ecole Polytechnique, 91128 Palaiseau, Cédex France 
symmetrical (see, e.g., [8]). The lack of symmetry will cause (often unwanted) mixed mode to occur [9]. On the other hand, systematic investigation of mixed-mode dynamic crack initiation can be achieved provided the crack-tip fields can be accurately determined [10]. Fracture time, is a key parameter which can be determined from fracture gage readings. For linear-elastic solids (brittle fracture), it has recently been shown that additional information is gained by using the reciprocity between the force and displacement based formulations [11]. Bulk fracture is thus defined as the time at which the evolutions of the SIF. determined using once the experimental forces and once the experimental displacements, diverge. Bulk fracture time is a useful complement to gage readings which generally precedes them by a few microseconds.

\section{Experimental}

We use an instrumented bar to apply and measure the transient forces and displacements applied to the specimen. As the striker impacts the bar a compressive pulse propagates towards the specimen. The pulse is then partly reflected-partly transmitted at the specimenbar interface [12].

Since the applied loading is unsymmetrical, mode mixity develops [10].

The setup for dominant I (CCS-Compact Compression Specimen) or II mode (shear) experiments is depicted schematically in Fig. 1.

\section{Results \& Discussion}

In this series of experiments, direct calculation of the SIFs was carried out using the dynamic weight function method. For each mode, we calculated the SIF from the convolution of the experimental force (or displacement) with the calculated response of the specimen subjected to a unit (dirac) force (or displacement) pulse. Typical evolutions of the I and II mode SIFs are shown in Figs. $2 \mathrm{a}$ and $\mathrm{b}$ for CCS and shear experiments respectively. From Fig. $2 \mathrm{a}$ it can be noted, as expected, that the mode II is minor although it may reach significant values. Fig. $2 \mathrm{~b}$ shows that the mode I component is essentially negative in accordance with previous reports $[4,13]$. 
The initial kink angle was measured locally from magnified pictures of the notch-tip. This measurement was delicate in several cases where the initial kink curves continuously. Yet it was observed that the macroscopic crack angle values can be considered as upper bound values with respect those obtained by local measurements. In all cases the initial kink angle increases with the impact velocity regardless of the dominant mode, as summarized in Table 1. The same trend was observed for the absolute values of the SIFs.

The reported results represent a systematic attempt to explore the two extremes of I-II modemix using the same experimental and theoretical methodology. To explain the observed kink angle-velocity relationship, one can invoke the maximum energy release rate criterion. For positive mode I this criterion is a maximum normal stress $\left(\sigma_{\theta \theta}\right)$ criterion [14].

Yet when the mode I component becomes negative, it can no longer be applied and onc can reasonably assumed that the crack will dissipate energy through a shear mechanism[15]. This amounts to searching for the angle at which the shear stress $\left(\sigma_{\mathrm{r}} \theta\right)$ is maximal.

The crack will ultimately select the initial kink angle corresponding to the maximum energy release rate, be it by combined opening + shear, or by shear alone. The stresses are determined from the experimental values of the SIF's [2]. A detailed description of the criterion will be presented in a subsequent paper. Next, the experimental results are analyzed using the proposed guidelines.

Fig. 3 describes the evolution of the kink angle as predicted from the criterion for two different velocities for mode I experiments. It can be noted that at times corresponding to bulk fracture, the predicted and observed angles are in good agreement. Here the operative mechanism is clearly mode I (opening) fracture.

Fig. 4 describes the evolution of the kink angle for mode II experiments. Fracture gage readings yield information of little accuracy as net separation of the two specimen halves occurs much after the actual fracture. Reciprocity-based estimates yield more reasonable values. In this case, we do not look for a prediction of the initial kink angle but rather use observed values in conjunction with the criterion's predictions. Fig. 4 shows a sharp transition in the kink angle values from low values (typically $10^{\circ}$ ) corresponding to a shear mechanism to high values (typically $65^{\circ}$ ). By comparing the bulk fracture times and the observed kink angles, it appears that at lower impact velocities, the shear specimens fail by a shear mechanism (mode II). By contrast mode I becomes energetically favorable at higher 
impact velocities and the initial kink angle is thus larger [4]. Therefore, the maximum energy release rate will dictate which of mode I or II crack initiation mechanism will operate.

Despite a certain simplification, as we deal with notches rather than sharp cracks (without frictional effects [15]), it seems that the present approach can predict the effect of the impact velocity on the initial kink angle.

\section{Conclusions}

- $\quad$ Dynamic crack initiation experiments were carried out on PMMA, as a model of brittle material.

- $\quad$ The mode mixity was systematically varied between dominant mode I and dominant mode II and a range of velocities was applied.

- The initial kink angle increases with the impact velocity independently of the dominant mode.

- $\quad$ The initial kink angle is reasonably well predicted in terms of a maximum stress criterion, i.e. maximum normal stress for combined opening + shear, and maximum shear stress for shear + negative opening (closure).

\section{Acknowledgment}

Daniel Rittel gratefully acknowledges financial support from the Israel Science Foundation and from the Technion VPR New York Metropolitan Research Fund.

\section{References}

1. Lawn, B. (1995), Fracture of Brittle Solids - Second Edition, Cambridge University Press, Cambridge.

2. L.B. Freund (1990), Dynamic Fracture Mechanics, Cambridge University Press, Cambridge .

3. Kalthoff, J.F. (1988), Shadow optical analysis of dynamic fracture, Optical Engng, 27, 835-840.

4. K. Ravi Chandar, (1995), "On the failure mode transitions in polycarbonate under dynamic mixed mode loading", International Journal of Solids and Structures, Vol. 32 No. 6/7, 925-938. 
5. Zhou, M., Rosakis, A.J. and Ravichandran, G., (1995), Dynamically propagating shear bands in impact-loaded prenotched plates, SM Report 94-01, California Institute of Technology, Pasadena CA.

6. Bui, H.D and Maigre, H. (1988), "Facteur d'intensité des contraintes tiré des grandeurs mécaniques globales", C.R. Acad.Sc. Paris, 306 II, 1213-1216.

7. Bui, H.D., Maigre, H. and Rittel, D. (1992). "A new approach to the experimental determination of the dynamic stress intensity factor., Int. J. Solids Structures, (29) No. 23, 2881-2895.

8. Giovanola, J.H. (1986). Investigation and application of the one-point-bend impact test, ASTM STP 905, Philadelphia PA.

9. Kalthoff, J.F. and Podleschny, R. (1992). On the nonsymmetry of the loading condition in Izod-type impact test configurations, in Proceedings of the International Symposium on Impact Engineering (Edited by I. Maekawa), 605610 , Sendai.

10. Maigre, H. and Rittel, D.(1993), Mixed-mode quantification for dynamic fracture initiation: application to the compact compression specimen., Int. J. Solids Structures, (30) No. 23, 3233-3244

11. Maigre, H., and Rittel, D. (1995), Dynamic fracture detection using the forcedisplacement reciprocity: application to the compact compression specimen, in press, Intl. Journal Fracture.

12. Rittel, D. and Maigre, H. (1993), A new approach to dynamic fracture toughness testing, in Novel Experimental Techniques in Fracture Mechanics (Edited by A. Shukla), 173-185, ASME-AMD Vol. 176, New York, NY.

13. Lee, Y.J. and Freund, L.B. (1990). Fracture initiation due to asymmetric impact loading of an edge cracked plate. J. Appl. Mech. 57, 104-111.

14. Nuismer, R.J., (1975). An energy release rate criterion for mixed mode fracture. Intl. Journal Fracture, Vol 11 No. 2, 245-250.

15. Broberg, K.B.(1983), in Workshop on Dynamic Fracture, California Institute of Technology, Feb. 17-18, 140-155 


\begin{tabular}{|c|c|c|c|c|c|c|}
\hline spec. & $V_{\text {imp }}$ & Igage & tbulk & obs. $\alpha$ & pred. $\alpha$ & mode \\
\hline & {$[\mathrm{m} / \mathrm{s}]$} & {$[\mu s]$} & {$[\mu s]$} & {$[0]$} & {$[0]$} & \\
\hline CCS5 & 10 & $87-87$ & $\leq 80$ & $20-22$ & $0-20$ & I \\
\hline $\mathrm{CCS} 4$ & 20 & $83-97$ & $\leq 70$ & $61-62$ & $\geq 30$ & I \\
\hline SHEAR2 & 14 & not used & $\approx 33$ & $\approx 10$ & $\approx 10$ & II \\
\hline SHEAR3 & 22 & not used & $\approx 49$ & $69-74$ & $>50$ & I \\
\hline
\end{tabular}

Table 1: Experimental results. CCS: compare observed and predicted angles. Shear, note the transition from mode II to mode I initiated kink with increased impact velocity.

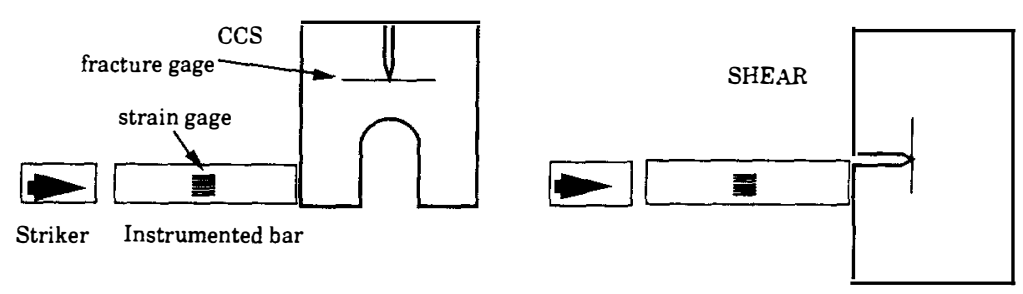

Figure 1: Experimental setup

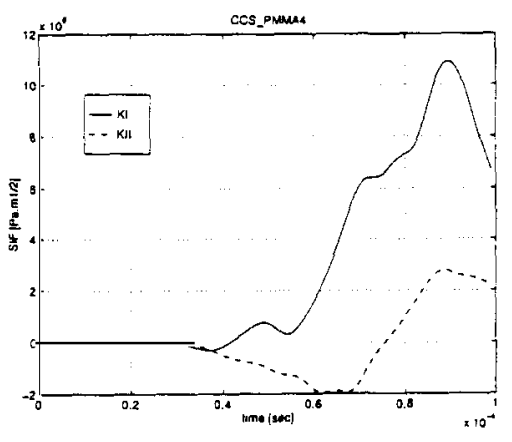

(a)

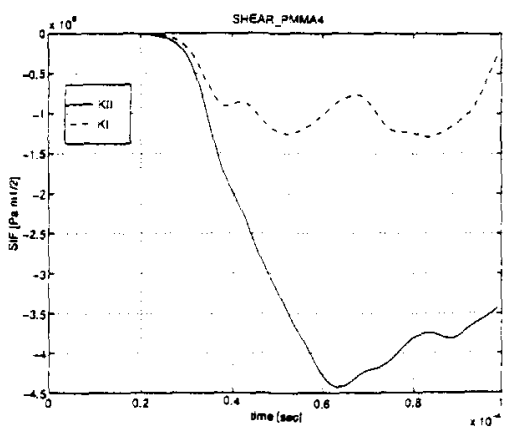

(b)

Figure2: Typical evolutions of dynamic $\mathrm{K}_{\mathrm{I}}$ and $\mathrm{K}_{\mathrm{II}}$ for CCS (a) and shear experiments (b). (Note the negative $K_{I}$ for shear experiments) 

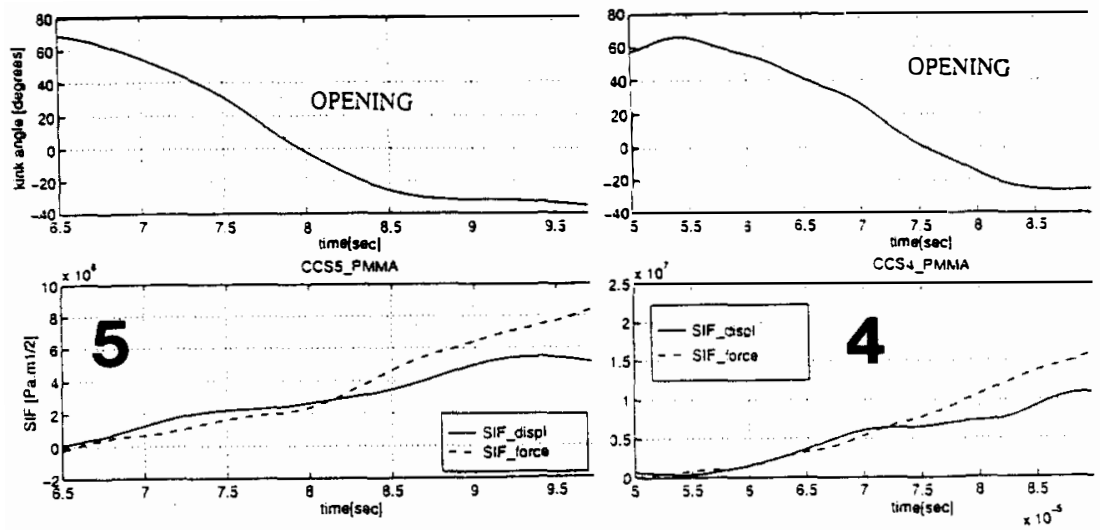

Eigure 3: Specimens CCS5 and CCS4. Evolutions of the mode I SIFs determined using experimental forces and displacements. Predicted kink angle as a function of time. Note the angle at bulk fracture time (divergence point, Table I).
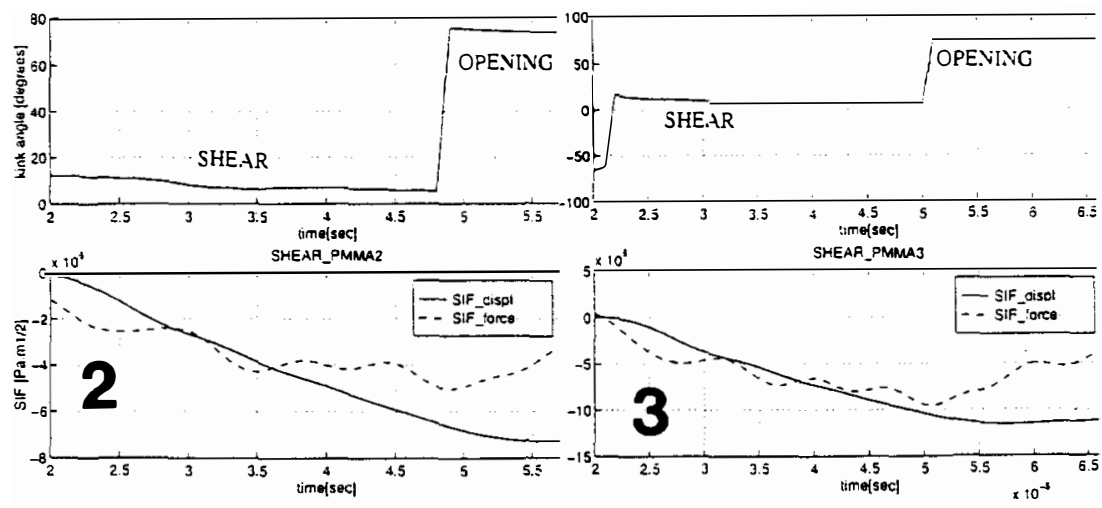

Figure 4: Specimens SHEAR2 and SHEAR3. Evolutions of the mode II SIFs determined using experimental forces and displacements. Predicted kink angle as a function of time. Note the angle at bulk fracture time and the shift in fracture mechanism (divergence point, Table I). 